Activation of 3-D CEMBS

L. Dzierzbicka-

Głowacka et al.

\title{
Activation of the operational ecohydrodynamic model (3-D CEMBS) - the hydrodynamic part
}

\section{Dzierzbicka-Głowacka, J. Jakacki, M. Janecki, and A. Nowicki}

Institute of Oceanology, Polish Academy of Sciences, Sopot, Poland

Received: 11 April 2012 - Accepted: 29 June 2012 - Published: 16 July 2012

Correspondence to: L. Dzierzbicka-Głowacka (dzierzb @iopan.gda.pl)

Published by Copernicus Publications on behalf of the European Geosciences Union.

Printer-friendly Version

Interactive Discussion 


\section{Abstract}

The paper presents a description of the hydrodynamic part of the coupled ice-ocean model that also includes ecosystem predictive model for evaluation of the condition of the marine environment and the Baltic ecosystem, as well as a preliminary empirical

5 verification of the operational hydrodynamic model based on the POP code in order to determine the consistence between the results obtained from the model and experimental results for the sea surface temperature.

The current Baltic Sea model is based on the Community Earth System Model (CESM from NCAR - National Center for Atmospheric Research). CESM was adopted 10 for the Baltic Sea as a coupled sea-ice model. It consists of the Community Ice Code (CICE model, version 4.0) and the Parallel Ocean Program (POP, version 2.1). The models are coupled through the coupler (CPL7), which is based on the Model Coupling Toolkit (MCT) routines. The current horizontal resolution is about $2 \mathrm{~km}$ (1/48 degrees). The ocean model has 21 vertical levels. The driver time step is $1440 \mathrm{~s}$ and it is also 15 coupling the time step. The ocean model time step is about $480 \mathrm{~s}$ ( $8 \mathrm{~min}$ ). Currently, the model is forced by fields from the European Center for Medium Weather Forecast. In the operational mode, 48-h atmospheric forecasts are used, which are supplied by the UM model of the Interdisciplinary Centre for Mathematical and Computational Modelling of the Warsaw University. The model of the marine ecosystem is the right tool for monitoring the state and bioproductivity of the marine ecosystem and forecasting the physical and ecological changes in the studied basin.

\section{Introduction}

The Baltic Sea is a very difficult basin for numerical modelling. On the one hand, the mesoscale phenomena require the whole basin to be included, on the other hand only very small spatial structures of bathymetry are of major significance on hydrology of the Baltic Sea. There is very strong vertical density stratification and the benthic zone

GMDD

$5,1851-1875,2012$

Activation of 3-D CEMBS

L. Dzierzbicka-

Głowacka et al.

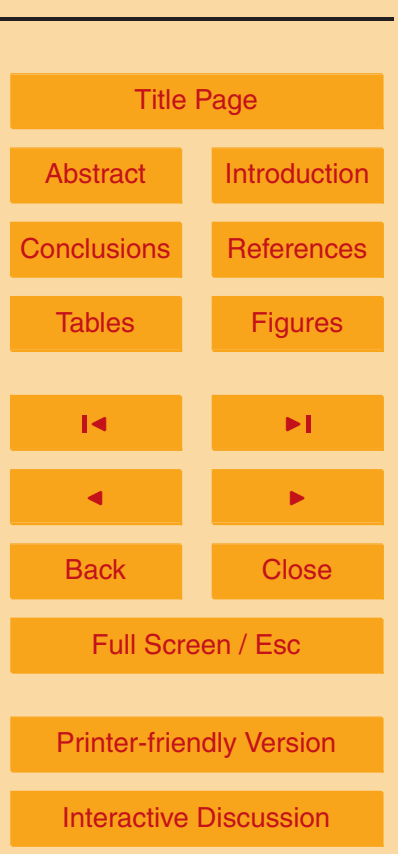

Interactive Discussion 
is important for transportation of inflow waters. For the water balance, it is necessary to include rivers and precipitation. Due to all these elements, a proper spatial scale and long-term simulation are required to obtain a good projection of the real state of the Baltic Sea. Changes in hydrological parameters and velocity fields are important in 5 large temporal scale - from days, through months to decades and even longer. These changes depend on short- and long-term changes in the atmosphere and in the ocean worldwide. Model calculations take into account changes in the time scale from days to decades. This is a direction of researches defined by BALTEX phase II, Analysis of changes and climate variability (BALTEX, 2006a,b). At present, the most modern 10 supercomputers allow to undertake such a difficult task, although certain simplifications are still necessary (Osinski, 2007).

Dzierzbicka-Głowacka and her co-workers published several papers adressed to modelling the hydrodynamical and biological processes, for instance: DzierzbickaGłowacka (2000), Dzierzbicka-Głowacka et al. (2006, 2010, 2011a,b). In 2011, the operational ecohydrodynamic model (3-D CEMBS) was launched at the Institute of Oceanology PAS in the parallel version on the $2 \mathrm{~km}$ grid with rivers and the open boundary for the hydrodynamic module.

This paper presents an integrated, operational model of the Baltic ecosystem - the hydrodynamic part with the ice component and the initial verification, the comparison

\section{3-D-CEMBS MODEL - a new version}

Community Climate System Model/Community Earth System Model (CCSM4.0/CESM1.0) consists of five separate components with an additional coupler (CPL7), which controls the time, exciting forces, domains, grids and exchanging information between models. The best descriptions of all used components (including updates) are on the CCSM4 website: http://www.cesm.ucar.edu/models/ccsm4.0/. For our purposes, CESM was adapted for the Baltic Sea and it is called Coupled

GMDD

$5,1851-1875,2012$

Activation of 3-D CEMBS

L. Dzierzbicka-

Głowacka et al.

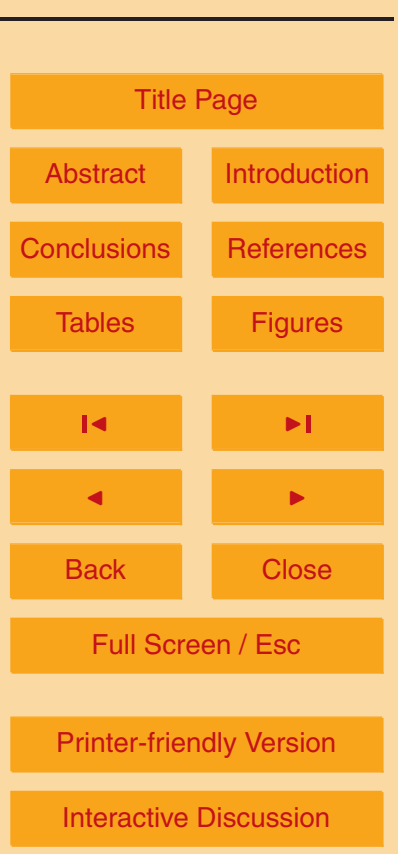

Interactive Discussion 
Ecosystem Model Baltic Sea (3-D CEMBS). However, it is not an entirely active configuration. The ocean model (Parallel Ocean Program, POP, version 2.1) and the ice model (Community Ice CodE - CICE, version 4.0) work in the active mode, and they are imposed by the model of atmospheric data (this part is called atmospheric 5 data model with the acronym datm7, see Fig. 1). Other models are excluded from this configuration (also called in the stub mode). The main task of datm7 is to interpolate atmospheric data into the model domain. 3-D-CEMBS is also consist of the ecosystem module (see Fig. 1) on which work is currently in progress.

The 3-D-CEMBS model is configured at two horizontal resolutions, about 9 and $2 \mathrm{~km}$ $10\left(1 / 12^{\circ}\right.$ and $1 / 48^{\circ}$ respectively). The model bathymetry is represented by 21 vertical levels and the thickness of the first four surface layers is equal to five metres (Table 1). The bottom topography was based on ETOPO1-1, arc-minute global relief model http: //www.ngdc.noaa.gov/mgg/global/global.html, National Geophysical Data Center). The bathymetric data were interpolated to the model grid using the kriging method. The initial state of the ocean model was prepared using temperature and salinity climatology data (Jansen et al., 1999). The ocean surface level ( $5 \mathrm{~m}$ deep) is restored based on the monthly timescale to the monthly average $T$ and $S$ climatology, as a correction term to the explicitly calculated fluxes and overlying atmosphere or sea ice. The restoring time was set to 30 days at the surface and 10 days at the domain boundary. 3-D-CEMBS domain is based on stereographic coordinates, but the equator of these coordinates is in the centre of the Baltic Sea (so we actually use rotated stereographic coordinates) and we can assume that cells are square and they have identical area.

The current calculations are performed on supercomputers of cluster type, like Galera, which is located at the Academic Computer Centre in Gdańsk (CI TASK).

The time needed for computing $1 \mathrm{yr}$ of the ecohydrodynamic model is $30 \mathrm{~h}$ on 16 processors for the $9 \mathrm{~km}$ resolution and $120 \mathrm{~h}$ on 256 processors for the $2 \mathrm{~km}$ resolution.

\section{GMDD}

$5,1851-1875,2012$

Activation of 3-D CEMBS

L. Dzierzbicka-

Głowacka et al.

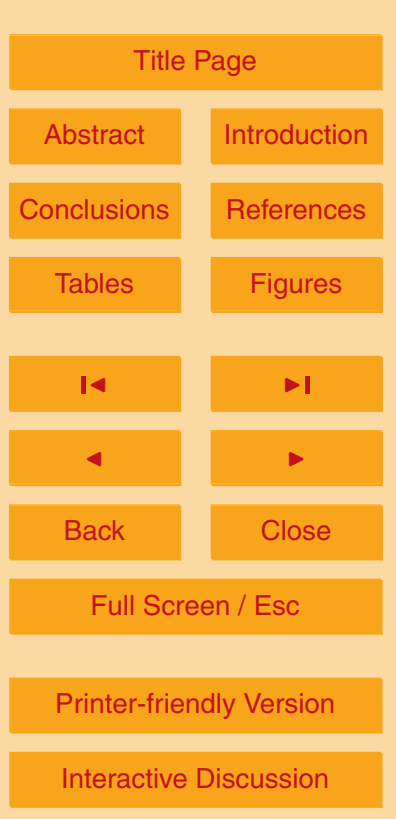




\subsection{The POP model}

The ocean model is based on the Parallel Ocean Program (POP, Smith and Gent, 2004) from the National Laboratory in Los Alamos (LANL), which is derived from the global ocean model (Semtner, 1974) with additional conditions for free surface (Kill-

5 worth et al., 1991). This is a model of " $z$ " type (identical thickness of layers for every cell); the three-dimensional equations describing the behaviour of the stratified ocean are solved by parametrization. Numerically the model defines spatial derivatives in the spherical coordinates using the method of finite elements. Physical quantities of the model are embedded in the spherical grid of Arakaw B (Arakawa and Lamb, 1977).

10 A preconditioned conjugate gradient solver (PCG) is used as the barotropic solver. The advection is represented by the center differential scheme. Parametrization of horizontal mixing is accomplished by a biharmonic operator, and vertical turbulence is determined by k-profile parametrization (KPP - Large et al., 1994). The equation of state, introduced by McDougall et al. (2003), is also used.

POP is a three-dimensional hydrodynamic model derived from the ocean model created in the late 1960s by Kirk Bryan (1969) and Michael Cox from the NOAA Geophysical Fluid Dynamics Laboratory in Princeton. The model was later modified and adapted by Semtner (1974) for vector processors. The whole class of models from which POP is called Bryan-Cox-Semtner type (B-C-S). The code of the model is adapted inter alia for supercomputers, but is well portable also for machines of different architecture, for example cluster types. The code of the POP model is characterised by good numerical performance and is well scalable on a large number of $\mathrm{O}(1000)$ processors (Jones et al., 2003).

Models derived from the family of B-C-S type are most commonly used for modelling the ocean. At present, models of B-C-S type are used in many research centres worldwide. Those are both regional models, e.g. for the Baltic Sea (Meier, 2005; Lehmann et al., 2004; Lass and Mohrholz, 2003; Rudolph and Lehmann, 2006), the Northern Atlantic (Brachet and Le Lost, 2004), the Arctic (Maslowski et al., 2004), and

GMDD

$5,1851-1875,2012$

Activation of 3-D CEMBS

L. Dzierzbicka-

Głowacka et al.

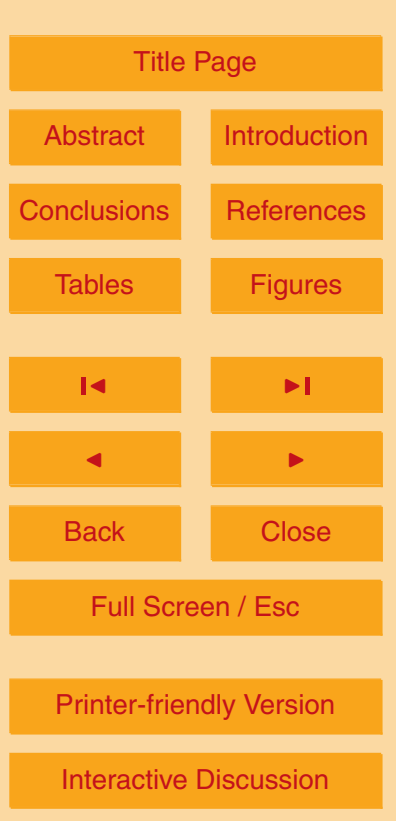

Interactive Discussion 
global models (Maltrud and McClean, 2005; Lee and Coward, 2003), which analyse processes in coastal waters (Lass et al., 2001) and in the open ocean, in short periods of time and small climatic scales (Nadiga et al., 2006; Bryan et al., 2006). In 2001, POP was adapted in the USA for the CCSM (Community Climate System Model) model as 5 an oceanic component.

\subsection{The CICE model}

Ice model is based on elastic-visco-plastic (EVP) rheology (Hunke and Dukowicz, 1997). It is designed to work in accordance with the POP ocean model using the parallel computing machines. It consists of several interactive elements: the thermodynamic model, which computes local growth rates of snow and ice owing to vertical conduction of energy and momentum fluxes. It also defines velocity of each ice cell based on wind and ocean velocity. It has a few vertical categories, so that the stress distribution is much closer to the real one.

CICE was applied worldwide in different configurations. It was used to study the variability and the impact of ice on the processes occurring in the atmosphere and the ocean on time scales ranging from decades to hundreds of years (Bitz and Lipscomb, 1999). It is used in regional models and global applications. It is used to study the cycle of carbon dioxide, in paleooceanography, and to study the physics and properties of the sea ice (Lipscomb and Hunke, 2004). Incorporation of the CICE model (version 4.0) into the regional POP model (version 2.1), completed within the scope of the research grant (No NN305111636 - the Polish State Committee for Scientific Research), is the first application of such an advanced ice model for the Baltic Sea. The detailed description of the ice model CICE (version 4.0) and its verification will be presented in a separate paper.

GMDD

$5,1851-1875,2012$

Activation of 3-D CEMBS

L. Dzierzbicka-

Głowacka et al.

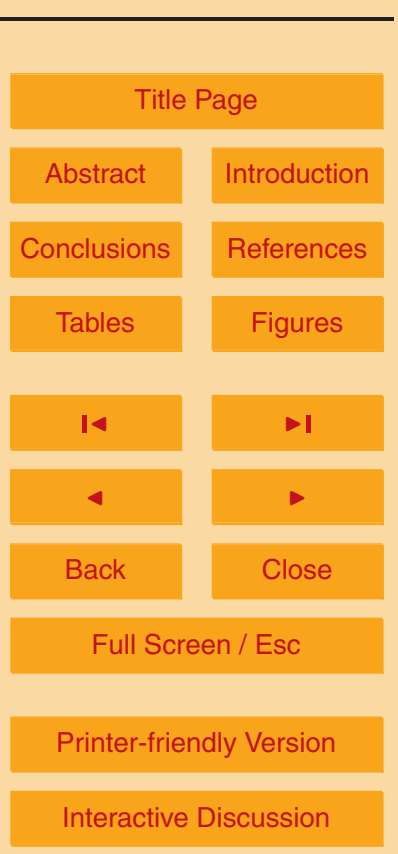




\subsection{The atmosphere - external forces}

The atmosphere contains exciting forces for the ocean and ice models. The atmospheric data come from ERA-40 reanalysis - daily average values for the period of $40 \mathrm{yr}$.

$5 \quad$ ERA-40 (ECMWF 40-yr Reanalysis; Uppala et al., 2005) coming from the European Centre for Medium-Range Weather Forecasts (ECMWF) is a reanalysis of meteorological observations for the period of September 1957-August 2002. The ERA-40 project incorporated all available observations, including satellite measurements, as well as the latest computing systems to create a consistent database (i.e. without implementation of changes for the entire computing period) for the past $40 \mathrm{yr}$ using one of the most modern models of the atmosphere. As evidenced by Omstedt et al. (2005), who compared also the forces from the Swedish Meteorological and Hydrological Institute $(\mathrm{SMHI})$. Only the low horizontal resolution $\left(2.5^{\circ} \times 2.5^{\circ}\right)$ causes that winds over the sea area are weaker than they are in fact.

15 To be able to use the ERA-40 data available on the numerical grid other than the grid of the Baltic model, it was necessary to interpolate the data. This interpolation was performed by applying two-dimensional spline functions of the third order (Press et al., 2001).

The operational system uses 48-h meteorological forecasts updated every $6 \mathrm{~h}$ from the UM model used by the Interdisciplinary Centre for Mathematical and Computational Modelling of the Warsaw University (ICM UW).

The model uses the following external fields:

- $2 \mathrm{~m}$ air temperature and specific humidity,

- sea level pressure,

25 - precipitation (rain and snow),

- short and long wave radiation downwards,

\section{Activation of 3-D} CEMBS

\section{Dzierzbicka-}

Głowacka et al.

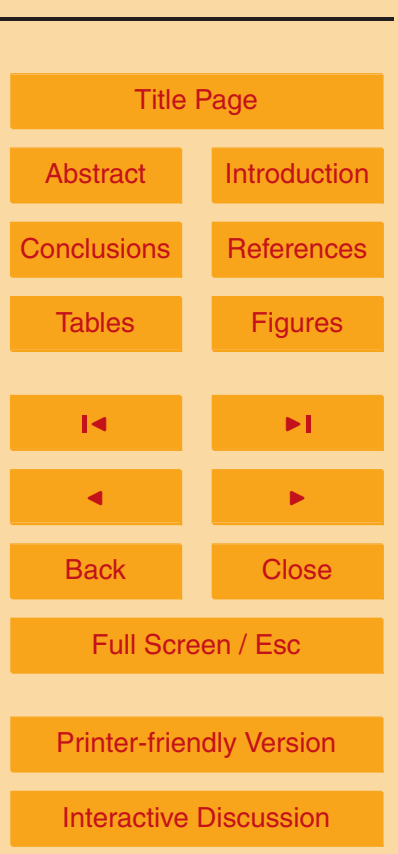


- wind speed at the level of $10 \mathrm{~m}$,

- air density.

GMDD

\subsection{River runoff}

Volume data on river discharge come from of the model Balt-HYPE of SMHI. Balt5 HYPE is a hydrological model to simulate the flows of water and substances from precipitation, through the earth into streams and lakes, up to the river mouths. River basins are divided into subregions, each subregion is further divided into classes according to land cover, soil type and altitude. Values of flows for the years 1971-2008 are available on the website http://balt-hypeweb.smhi.se/. Seventy-one rivers were included in the model. Catchment areas of most inserted rivers are located in the territory of Sweden (34 rivers) and Finland (25 rivers). Furthermore, rivers from the territory of Estonia (4), Latvia (3), Poland (2), Lithuania (1), Russia (1) and Norway (1) were also included. The detailed description of river discharge included in the model will be presented in a different paper.

\subsection{Lateral boundary conditions}

The Baltic domain used both in the ice and ocean model in 3-D CEMBS is closed for the computing reasons at the junction between the Baltic and the North Sea, i.e. near Skagerrak.

In order to obtain the correct flows (including inflows into the Baltic Sea), it was necessary to create a flow in the Strait of Skagerrak, which would depend on the model time. In practice, each method has advantages and disadvantages, therefore it is good to use more than one method simultaneously. Basically, three methods were combined in order to determine the correct flows:

- classic Dirichlet condition that includes the external data

\section{Activation of 3-D} CEMBS

\section{Dzierzbicka-}

Głowacka et al.

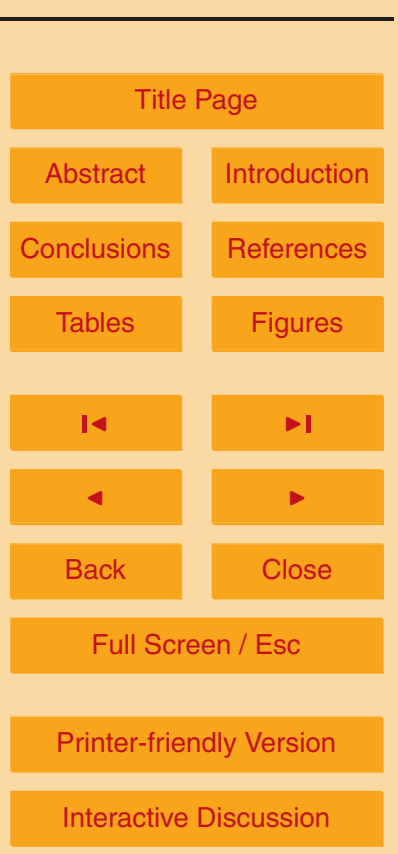




\subsection{The operational system}

To ensure the systematic operation of this model, it was necessary to prepare a fully automatic system that supports it. The work of the system is divided into a few stages.

5 The first one consists in collecting and preparing the atmospheric data used by this model. These data are retrieved from the servers of ICM UW. They include 48-h meteorological forecasts updated every $6 \mathrm{~h}$. After data are downloaded, a series of processes follow, which aim at their adaptation to the requirements of the model. In addition, the data are archived and backup on local disks. Next, model restart parameters are defined. Then the model starts and monitor the performance of the model, which is followed by retrieval of the results and storing them in the archive and on the website (http://deep.iopan.gda.pl/CEMBaltic/new_lay/index.php). The detailed description of the system is presented in a separate paper.

\section{Results}

15 In the first half of 2011, the new CESM model was adapted for the Baltic domain. Models have been adapted and work properly (see the website of this model). The results of 48-h forecast simulations for the area and point are presented for the two model configurations described above (Fig. 2). At present, the following parameters are available: temperature, salinity, water currents, the sea level and the ice area cover.

20 The examples of simulations of 48 -h forecast for $2 \mathrm{~km}$, for the selected subareas and points are presented on Fig. 2 for the following situations:

1. For the area forecast start: 5 March 2012, 18:00 UTC.

Select forecast parameters: hour: +6 (forecast is for 6 March 2012, 00:00 UTC), variable: currents $\left(\mathrm{cm} \mathrm{s}^{-1}\right)$; depth: $20-26 \mathrm{~m}$ (5th layer), coordinate $X: 187$ to 425 ,
GMDD

$5,1851-1875,2012$

Activation of 3-D CEMBS

L. Dzierzbicka-

Głowacka et al.

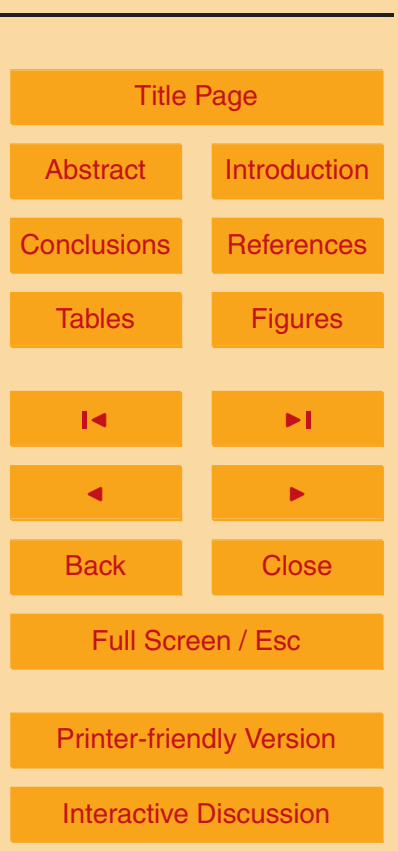


coordinate $Y: 32$ to 168 . After selection of parameters, press: Submit and the screen will show a drawing with results of the model.

2. For the point forecast start: 5 March 2012, 12:00 UTC.

Select the depth and a point on the map to get $48 \mathrm{~h}$ time series of temperature and salinity.

\subsection{Initial validation}

Preliminary tests were performed to validate the model on the $2 \mathrm{~km}$ grid.

Temperature. Figure 3 presents the vertical distribution of temperature measured at the end of summer 2000 in the Baltic Sea, performed using Richardson vertical mixing 10 (Fig. 4a) and k-profile parametrization (KPP) (Fig. 4b). As it appears from the presented results, KPP best reflects the temperature distribution in the Baltic Sea in August (on the model results, the depth is presented as levels; the first four levels are $5 \mathrm{~m}$ thick). The comparison of other years gives similar results. Based on the performed tests, it was decided that in the case of the Baltic Sea, KPP is the best parametrization of vertical mixing, and it was also applied in the hydrodynamic and biological model.

In addition, simulations were performed with historical data, which were compared with the model data (results from the models 3-D CEMBS and SMHI, see Fig. 5 in Meier, 2002) and the experimental data (on four measuring buoys located at the Baltic Sea, Fig. 5) from HELCOM http://ocean.ices.dk/helcom/Helcom.aspx?Mode=1 and SMHI http://www.smhi.se/oceanografi/oce_info_data/SODC/download_en.htm.

The simulations and measurements in 1963-2007 were compared. In respect of all the parameters, the correlations of the observed regularities decreased from the surface to the bottom. The consistency of the calculated values with the measured distribution was particularly good with regard to temperature. These results also testified to the fact that the environmental conditions did not change radically and the simulated processes were regular.

GMDD

$5,1851-1875,2012$

Activation of 3-D CEMBS

L. Dzierzbicka-

Głowacka et al.

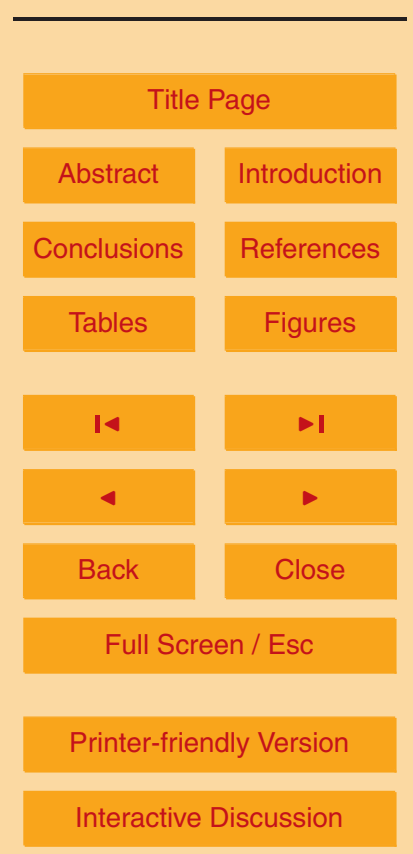

Interactive Discussion 
Figure 6 present results of the model for sea-surface temperature. The modelled values of this temperature $\left(T_{\bmod }\right.$ - the value from the first layer $-5 \mathrm{~m}$ ) were compared with values measured in situ ( $T_{\text {exp }}$ - the sea-surface temperature) at particular measurement stations and the estimated errors set out in Table 2.

5 The calculated mean errors (systematic and statistical) are in the investigated region of the Baltic Sea of -0.05025 and \pm 1.33 , respectively. Also, the Pearson productmoment correlation coefficient was used to compare the model results of the sea surface temperature with the measurements (see Table 2, last column). The mean value of correlation coefficient for four points was 0.97035 for the long-time 1963-2007.

10 As far as diagnosing the state of the Baltic ecosystem is concerned, this level of accuracy is satisfactory, because the model state parameters are calculated for the whole cell (an area of $\sim 4 \mathrm{~km}^{2}$ ), not for particular points at sea where in situ measurements were performed.

Additionally, comparing results from Meier's (2002, Fig. 5) and our model for the 15 period 1980-1994 both models show very similar results. It was presented during 8th Baltic Sea Science Congres (Janecki et al., 2011).

The presented results indicate high conformity of a new adopted model, both with other models and with experimental data.

Ice component. Temporal ice cover is a significant element in the modelling of the

Baltic Sea. The ice cover prevents the exchange of momentum and heat fluxes between the atmosphere and the sea. The northern Baltic (the Gulf of Bothnia, the Bothnian Sea, the Gulfs of Riga and Finland) is covered with ice every winter, whereas the southern Baltic - only during severe winters. In winter with average severity, $45 \%$ of the Baltic Sea is covered with ice, which in the northern regions of the sea remains for half a year. As we noticed before, this model consist of the ice model (CICE) as an active component. Results from the ice model are not the main focus of this paper, thus we will show only a comparison between the operational model and the observed Baltic Sea ice state from Baltic Sea meteorological services. Ice concentration from
GMDD

$5,1851-1875,2012$

Activation of 3-D CEMBS

L. Dzierzbicka-

Głowacka et al.

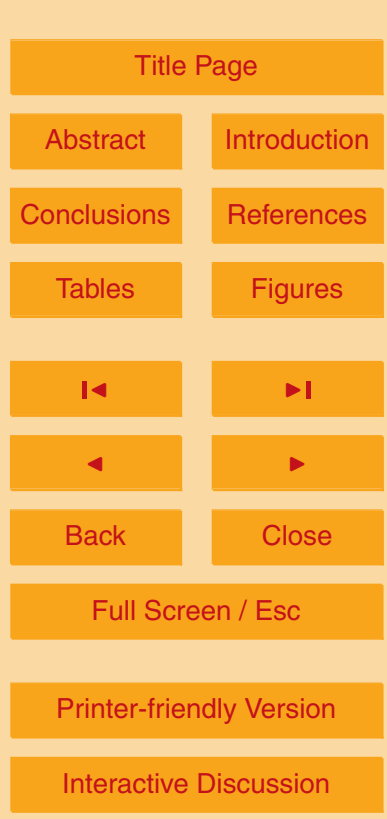


both sources is presented in Fig. 7. It is clean visible that there is good agreement between real ice concentration and model results.

GMDD

$5,1851-1875,2012$

\section{Conclusions}

At present one of the most important aspects of the oceanological studies is monitoring 5 the state and bioproductivity of marine ecosystems. Bioproductivity plays a considerable role in local and global changes. They are difficult to assess as the knowledge of mechanisms affecting the biological production and the functional relations between physiological processes in zooplankton species is required, as well as understanding of environmental parameters in the sea and how they influence the food chain.

10 To study the complexity of hydrophysical and biological processes in the marine environment, and the links between these processes, modern techniques, i.e. mathematical modelling and computer simulations are required. Although the field work provides the most reliable information on these mechanisms and processes, it requires comprehensive and costly in situ observations conducted under a variety of hydrological 15 conditions for long periods of time. They are nevertheless essential for the collection of sufficient statistical data for an adequate diagnosis of the state of the environment and for forecasts. Variables presented on the website for 48-h forecast are as follows: temperature, salinity, currents, sea surface height and ice area cover.

The 3-D CEMBS model (at present - the hydrodynamic module) is a suitable tool 20 for studying the annual, seasonal, monthly and daily variability of environmental parameters in the southern Baltic Sea. It can therefore be applied in the forecasting of ecological changes in the Baltic.

In order to assess the accuracy of the CEMBS model for the determination of parameters of the Baltic ecosystem, the detailed comparison of the model results with measurements will be presented by us in a separate paper.

The next step in our modelling work is to run the operational system for the biological module on the $2 \mathrm{~km}$ grid with the assimilation of satellite data (a separate paper). We

\section{Activation of 3-D CEMBS \\ L. Dzierzbicka- \\ Głowacka et al.}

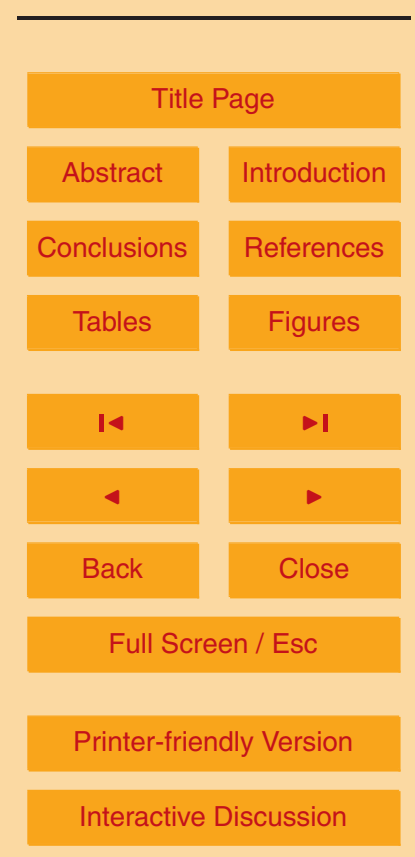

Interactive Discussion 
also intend to run the ecosystem model within the population model to study the impact of climate changes on the development of the most important species of calanoid copepods in the Baltic Sea.

Modelling is a very important element of the project SatBattyk (within which this 5 model is to be applied), because in the regions situated in temperate latitudes, the amount of data on the sea colour is limited by clouds. Therefore, models assimilating the satellite data are going to be an important part of the SatBałtyk project.

Acknowledgement. The study was financially supported by the Polish State Committee of Scientific Research (grants: No N N305 111636, N N306 353239). The partial support for this study 10 was also provided by the project Satellite Monitoring of the Baltic Sea Environment - SatBattyk founded by European Union through European Regional Development Fund contract no. POIG 01.01.02-22-011/09.

\section{References}

Arakawa, A. and Lamb, V. R.: Computational design of the basic dynamic processes of the 15

BALTEX: BALTEX Phase I 1993-2002, State of the Art Report, Inter. BALTEX Secr. Publ., Helmholtz-Zentrum Geesthacht, Germany, 34, 181 pp., 2005.

BALTEX: BALTEX Phase II 2003-2012. Science Framework and Implementation Strategy, BALTEX Secr. Publ., Helmholtz-Zentrum Geesthacht, Germany, 35, 90 pp., 2006a.

BALTEX: Assessment of climate change for the Baltic Sea basin - The BACC Project, BALTEX Secr. Publ., Helmholtz-Zentrum Geesthacht, Germany, 35, 26 pp., 2006b.

Bitz, C. M. and Lipscomb, W. H.: An energy-conserving thermodynamic sea ice model for climate study, J. Geophys. Res., Ocean, 104, 15669-15677, 1999.

Brachet, S. and Le Traon, P. Y.: Mesoscale variability from a high-resolution model and from altimeter data in the North Atlantic Ocean, J. Geophys. Res., 109, C12025, doi:10.1029/2004JC002360, 2004.

Bryan, F. O., Danabasoglu, G., Gent, P. R., and Lindsay, K.: Changes in ocean ventilation during the 21st century in the CCSM3, Ocean Model., 15, 141-156, 2006.
GMDD

5, 1851-1875, 2012

\section{Activation of 3-D} CEMBS

\section{Dzierzbicka-}

Głowacka et al.

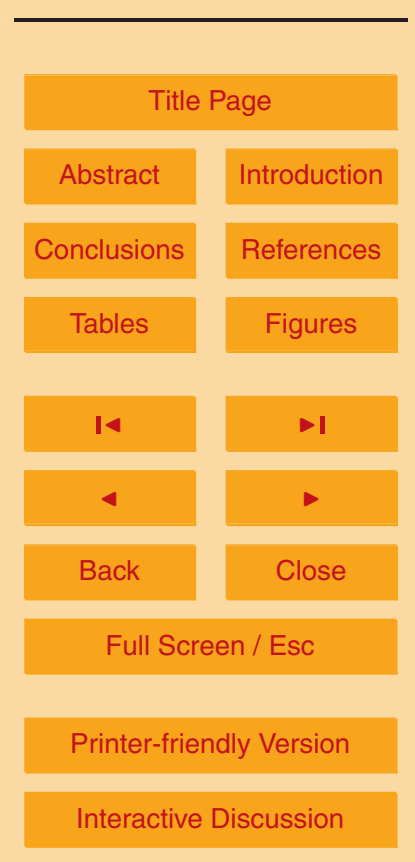


Bryan, K. A.: Numerical method for the study of the circulation of the World Ocean, J. Comput. Phys., 4, 347-376, 1969.

Climatological Ice Atlas for the Baltic Sea, Kattegat, Skagerrak and Vänern (1963-1979), Swedish Meteorological and Hydrological Institute (SMHI), Sweden, Norrkoping, 220 pp., 1982.

Dzierzbicka-Głowacka, L.: Mathematical modelling of the biological processes in the upper layer of the sea, Diss. Monogr. 13, Institute of Oceanology, PAS, Sopot, 124 pp., 2000.

Dzierzbicka-Głowacka, L., Bielecka, L., and Mudrak, S.: Seasonal dynamics of Pseudocalanus minutus elongatus and Acartia spp. in the southern Baltic Sea (Gdańsk Deep) - numerical 10 simulations, Biogeosciences, 3, 635-650, doi:10.5194/bg-3-635-2006, 2006.

Dzierzbicka-Glowacka, L., Żmijewska, I. M., Mudrak, S., Jakacki, J., and Lemieszek, A.: Population modelling of Acartia spp. in a water column ecosystem model for the South-Eastern Baltic Sea, Biogeosciences, 7, 2247-2259, doi:10.5194/bg-7-2247-2010, 2010.

Dzierzbicka-Głowacka, L., Kulinski, K., Maciejewska, A., Jakacki, J., and Pempkowiak, J.: Nu15 merical modelling of POC dynamics in the Southern Baltic under possible future conditions determined by nutrients, light and temperature, Oceanologia, 53, 971-992, 2011a.

Dzierzbicka-Głowacka, L., Jakacki, J., Janecki, M., and Nowicki, A.: Variability in the distribution of phytoplankton as affected by changes to the main physical parameters in the Baltic Sea, Oceanologia, 53, 449-470, 2011b.

20 Hunke, E. C. and Dukowicz, J. K.: An elastic-viscous-plastic model for sea ice dynamics, J. Phys. Oceanogr., 27, 1849-1867, 1997.

Jansen, F., Schrum, C., and Backhaus, J. O.: A climatological data set of temperature and salinity for the Baltic Sea and the North Sea, Dt. Hydrogr. Z., Supplement 9, 245 pp., 1999.

Jones, P. W., Worley, P. H., Yoshida, Y., White, J. B., and Levesque, J.: Practical performance portability in the parallel ocean program (POP) Concurrency Computat., Pract. Exper., 1, $1-15,2003$.

Killworth, P. D., Stainforth, D., Webb, D. J., and Paterson, S. M.: The development of a freesurface Bryan-Cox-Semtner ocean model, J. Phys. Oceanogr., 21, 1333-1348, 1991.

Large, W. G., McWilliams, J. C., and Doney, S. C.: Oceanic vertical mixing: a review and a model

$30 \quad$ with a nonlocal boundary layer parameterization, Rev. Geophys., 32, 363-403, 1994.

Lass, H. U. and Mohrholz, V.: On dynamics and mixing of inflowing saltwater in the Arkona Sea, J. Geophys. Res., 108, 3042, doi:10.1029/2002JC001465, 2003.

GMDD

$5,1851-1875,2012$

\section{Activation of 3-D} CEMBS

\section{Dzierzbicka-}

Głowacka et al.

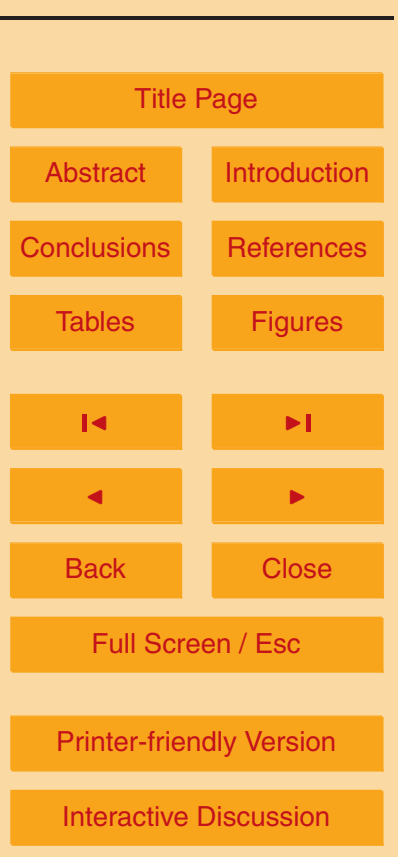


Lass, H. U., Mohrholz, V., and Seifert, T.: On the dynamics of the Pomeranian Bight, Cont. Shelf Res., 21, 1237-1261, 2001.

Lee, M. M. and Coward, A.: Eddy mass transport for the Southern Ocean in an eddy-permitting global ocean model, Ocean Model., 5, 249-266, 2003.

5 Lehmann, A., Lorenz, P., and Jacob, D.: Modelling the exceptional Baltic Sea inflow events in 2002-2003, Geophys. Res. Lett., 31, L21308, doi:10.1029/2004GL020830, 2004.

Lipscomb, W. H. and Hunke, E. C.: Modeling sea ice transport using incremental remapping, Mon. Weather Rev., 132, 1341-1354, 2004.

Maltrud, M. E. and McClean J. L.: An eddy resolving global $1 / 10^{\circ}$ ocean simulation, Ocean Model., 8, 31-54, 2005.

Maslowski, W., Marble, D., Walczowski, W., Schauer, U., Clement, J. L., and Semtner, A. J.: On climatological mass, heat, and salt transports through the Barents Sea and Fram Strait from a pan-Arctic coupled ice-ocean model simulation, J. Geophys. Res., 109, C03032, doi:10.1029/2001JC001039, 2004.

15 McDougall, T. J., Jackett, D. R., Wright, D. G., and Feistel R.: Accurate and computationally efficient algorithms for potential temperature and density of seawater, J. Atmos. Ocean. Tech., 20, 730-741, 2003.

Meier, H. E. M.: Modeling the age of Baltic Seawater masses: quantification and steady state sensitivity experiments, J. Geophys. Res., 110, C02006, doi:10.1029/2004JC002607, 2005.

20 Meier, H. E. M.: Regional ocean climate simulations with a 3D ice-ocean model for Baltic Sea. Part1: Model experiments and results for temperature and salinity, Clim. Dynam., 19, 237253, 2002.

Moore, A. W., Jan, L. Y., and Jan, Y. N.: Hamlet, a binary genetic switch between single- and multiple-dendrite neuron morphology, Science, 297, 1355-1358, 2002.

Nadiga, B. T., Taylorb, M., and Lorenzc, J.: Ocean modelling for climate studies: eliminating short time scales in long-term, high-resolution studies of ocean circulation, Math. Comput. Model., 44, 870-886, 2006.

Omstedt, A., Chen, Y., and Wesslander, K.: A comparison between the ERA40 and the SMHI gridded meteorological databases as applied to Baltic Sea modeling, Nord. Hydrol., 36, 369380, 2005.

Osinski, R.: Symulacja procesów dynamicznych w Morzu Battyckim zintegrowanym modelem ocean-lód, Ph.D. thesis, Institute of Oceanology, Polish Academy of Sciences, Sopot, Poland, 2007 (in Polish).

GMDD

5, 1851-1875, 2012

Activation of 3-D CEMBS

L. Dzierzbicka-

Głowacka et al.

Title Page

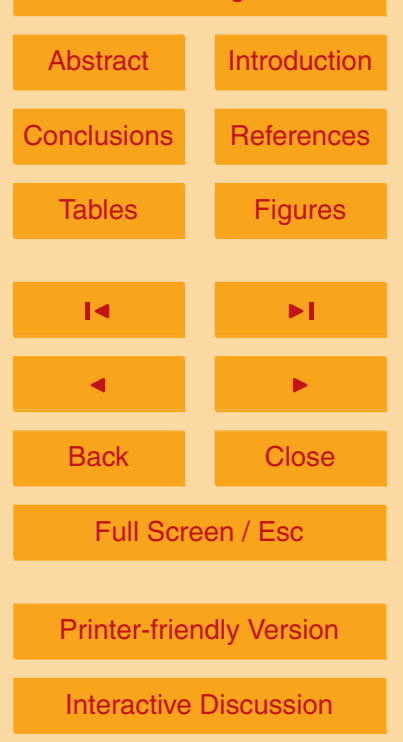

Interactive Discussion 
Press, W. H., Teukolsky, S. A., Vetterling, W. T., and Flannery, B. P.: Numerical Recipes in Fortran 77: The Art of Scientific Computing, Cambrige University Press, New York, USA, 921 pp., 2001.

Rudolph, C. and Lehmann, A.: A model-measurements comparison of atmospheric forcing and surface fluxes of the Baltic Sea, Oceanologia, 48, 333-360, 2006.

Semtner, A. J.: A general circulation model for the World Ocean, UCLA Dept. of Meteorology, Tech.Rep., No.8, 99 pp., 1974.

Smith, R. and Gent, P.: Reference manual for the parallel ocean program (POP), Los Alamos National Lab., New Mexico, 75 pp., 2004.

Uppala, S. M., Kållberg, P. W., Simmons, A. J., Andrae, U., da Costa Bechtold, V., Fiorino, M., Gibson, J. K., Haseler, J., Hernandez, A., Kelly, G. A., Li, X., Onogi, K., Saarinen, S., Sokka, N., Allan, R. P., Andersson, E., Arpe, K., Balmaseda, M. A., Beljaars, A. C. M., van de Berg, L., Bidlot, J., Bormann, N., Caires, S., Chevallier, F., Dethof, A., Dragosavac, M., Fisher, M., Fuentes, M., Hagemann, S., Hólm, E., Hoskins, B. J., Rayner, N. A Saunders, R. W. Simon, P., Sterl, A Trenberth, K. E Untch, A Vasilievic, D., Rayner, N. A., Saunders, R. W., Simon, P., Sterl, A., Trenberth, K. E., Untch, A., Vasiljevic, D., Viterbo, P., Woollen, J.: The ERA-40 re-analysis, Q. J. Roy. Meteor. Soc., 131, 2961-3012, doi:10.1256/qj.04.176, 2005.

\section{GMDD}

\section{$5,1851-1875,2012$}

\section{Activation of 3-D CEMBS}

\section{Dzierzbicka-}

Głowacka et al.

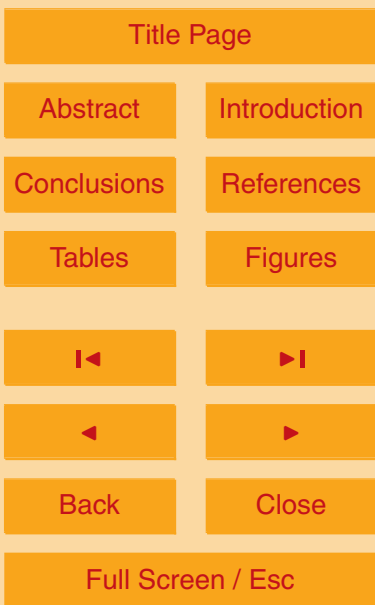

Printer-friendly Version

Interactive Discussion 
Table 1. Vertical resolutions.

\begin{tabular}{lrrr}
\hline Model level & Thickness & Lower depth & Mid-depth \\
\hline 1 & 5.0 & 5.0 & 2.5 \\
2 & 5.0 & 10.0 & 7.5 \\
3 & 5.0 & 15.0 & 12.5 \\
4 & 5.0 & 20.0 & 17.5 \\
5 & 6.0 & 26.0 & 23.0 \\
6 & 7.3 & 33.3 & 29.7 \\
7 & 8.8 & 42.1 & 37.7 \\
8 & 10.6 & 52.7 & 47.4 \\
9 & 12.8 & 65.4 & 59.1 \\
10 & 15.4 & 80.8 & 73.2 \\
11 & 18.6 & 99.4 & 90.1 \\
12 & 22.4 & 121.8 & 110.6 \\
13 & 27.0 & 148.9 & 135.4 \\
14 & 32.6 & 181.5 & 165.2 \\
15 & 39.3 & 220.8 & 201.2 \\
16 & 47.5 & 268.3 & 244.6 \\
17 & 57.3 & 325.5 & 296.9 \\
18 & 69.1 & 394.6 & 360.1 \\
19 & 83.3 & 477.9 & 436.3 \\
20 & 100.5 & 578.4 & 528.2 \\
21 & 121.6 & 700.0 & 639.2 \\
\hline
\end{tabular}

5, 1851-1875, 2012

Activation of 3-D CEMBS

L. Dzierzbicka-

Głowacka et al.

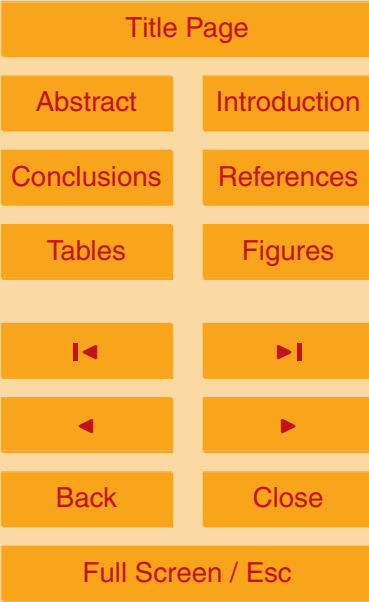

Printer-friendly Version

Interactive Discussion 


\section{GMDD}

$5,1851-1875,2012$

\section{Activation of 3-D CEMBS}

L. Dzierzbicka-

Table 2. Absolute errors and correlation coefficients in estimating the sea surface temperatures on the basis of modelled data from CEMBS model for four selected points: BY5 - Bornholm Deep, BY15 - Gotland Deep, LL07 - Gulf of Finland and SR5 - Bothnian Sea.

\begin{tabular}{lrrr}
\hline & \multicolumn{2}{c}{ Arithmetic statistics } & \\
\cline { 2 - 3 } Point & $\begin{array}{r}\text { Systematic error } \\
\langle\varepsilon\rangle\left({ }^{\circ} \mathrm{C}\right)\end{array}$ & $\begin{array}{r}\text { Statistical error } \\
\sigma_{\varepsilon}\left({ }^{\circ} \mathrm{C}\right)\end{array}$ & $\begin{array}{r}\text { Correlation } \\
\text { coefficient }\end{array}$ \\
\hline BY5 & 0.479 & \pm 1.05 & 0.9821 \\
BY15 & 0.17 & \pm 1.10 & 0.9815 \\
LL07 & -1.07 & \pm 1.80 & 0.9518 \\
SR5 & 0.22 & \pm 1.37 & 0.9660 \\
\hline
\end{tabular}

Title Page

Abstract

Introduction

Conclusions

References

Tables

Figures

14

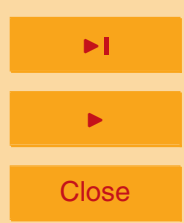

Back

Close

Full Screen / Esc

Printer-friendly Version

Interactive Discussion 


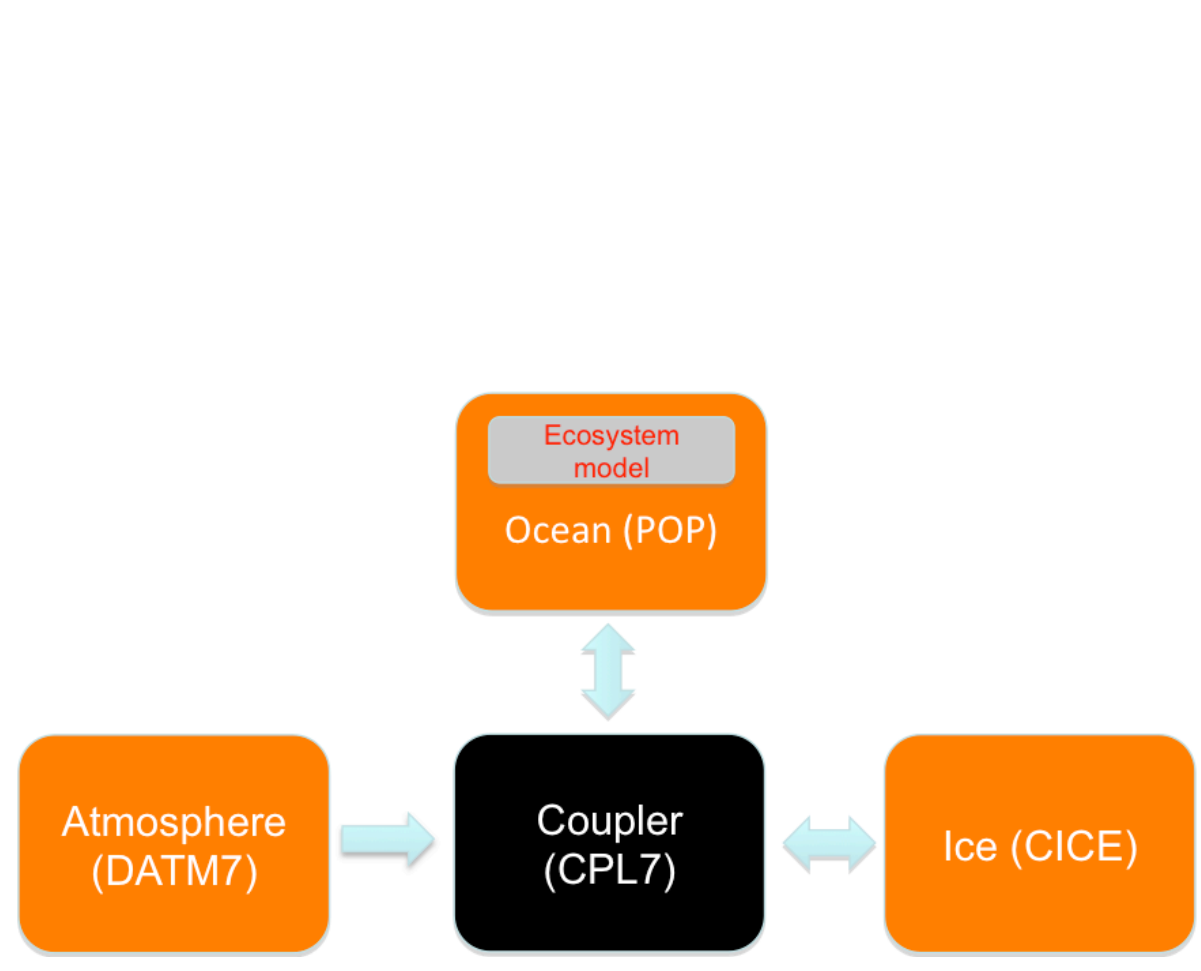

\section{GMDD}

5, 1851-1875, 2012

\section{Activation of 3-D CEMBS \\ L. Dzierzbicka- \\ Głowacka et al.}

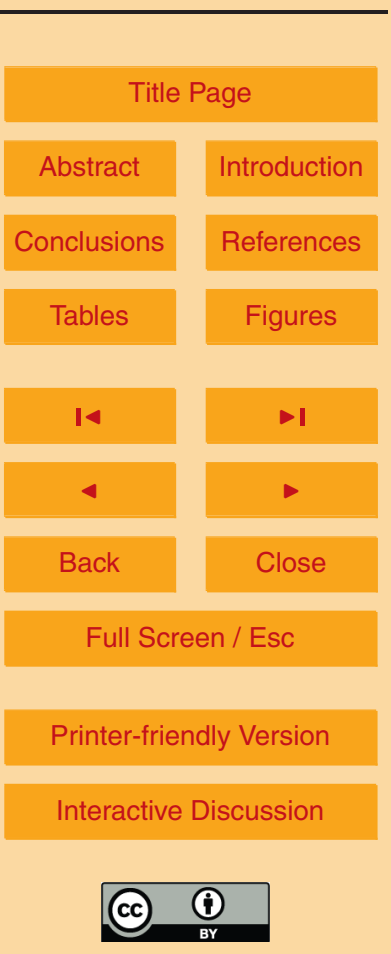




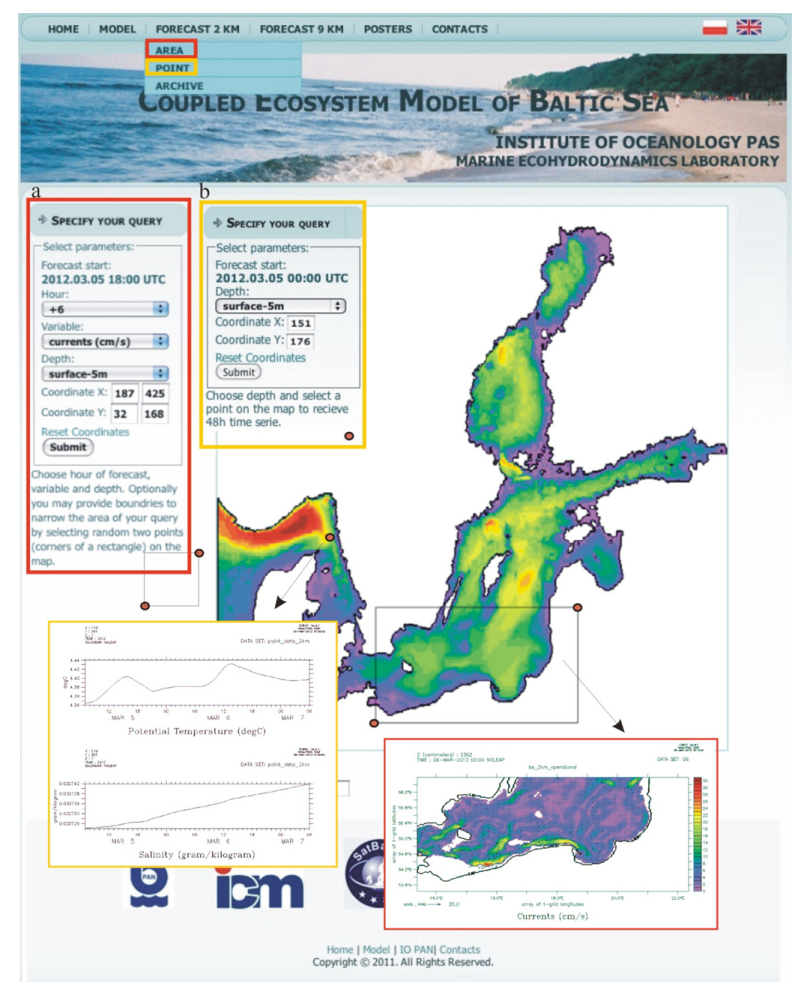

Fig. 2. The selection page with results of 3-D CEMBS model for the area (a) and for $48 \mathrm{~h}-$ point (b).

\section{GMDD}

$5,1851-1875,2012$

\section{Activation of 3-D CEMBS \\ L. Dzierzbicka- \\ Głowacka et al.}

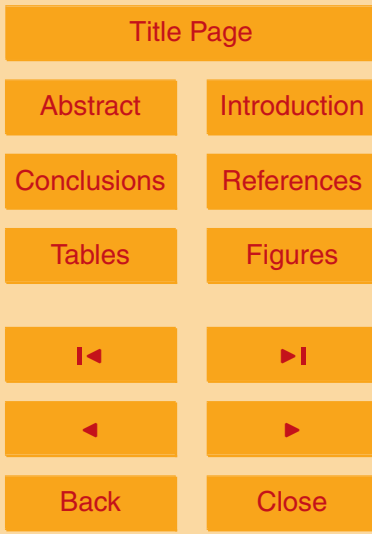

Full Screen / Esc

Printer-friendly Version

Interactive Discussion 


\section{GMDD}

\section{$5,1851-1875,2012$}

\section{Activation of 3-D CEMBS \\ L. Dzierzbicka- \\ Głowacka et al.}

R.v. 'Oceania', August 18-19, 2000

Temperature $\left[{ }^{\circ} \mathrm{C}\right]$

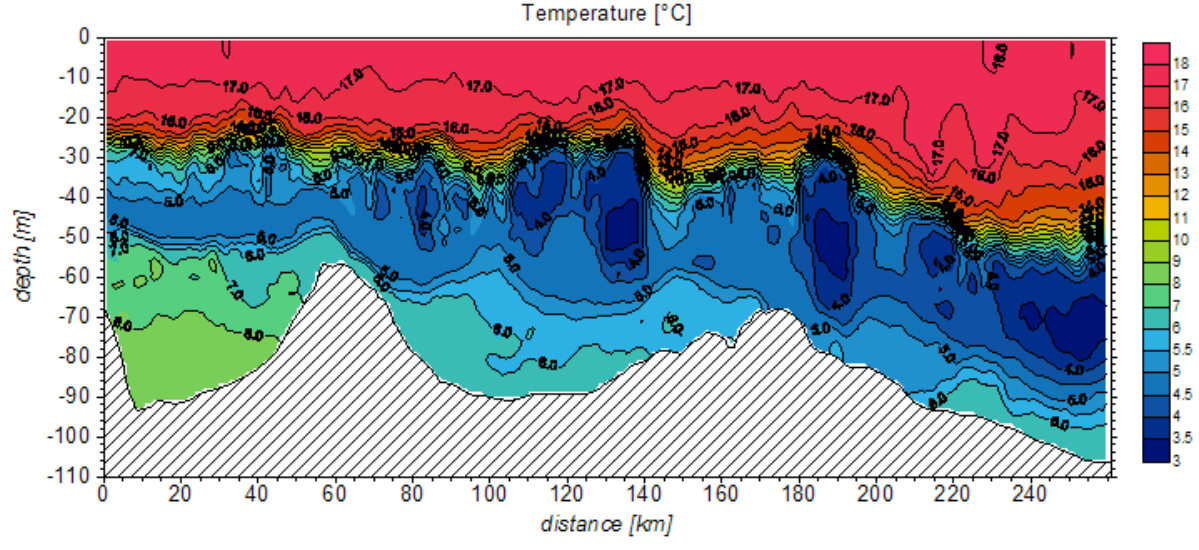

Fig. 3. The temperature profile measured in the Baltic Sea in August 2000 (the measurement taken at the Institute of Oceanology of Polish Academy of Sciences).

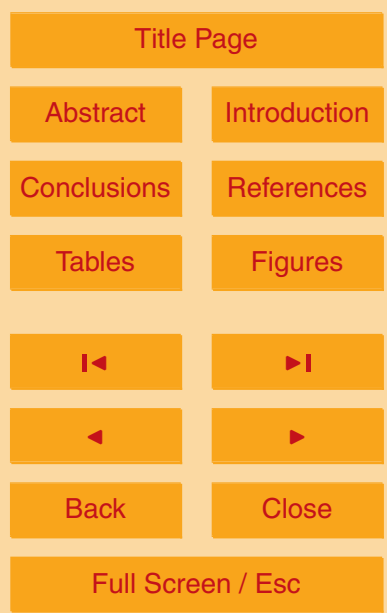

Printer-friendly Version

Interactive Discussion 


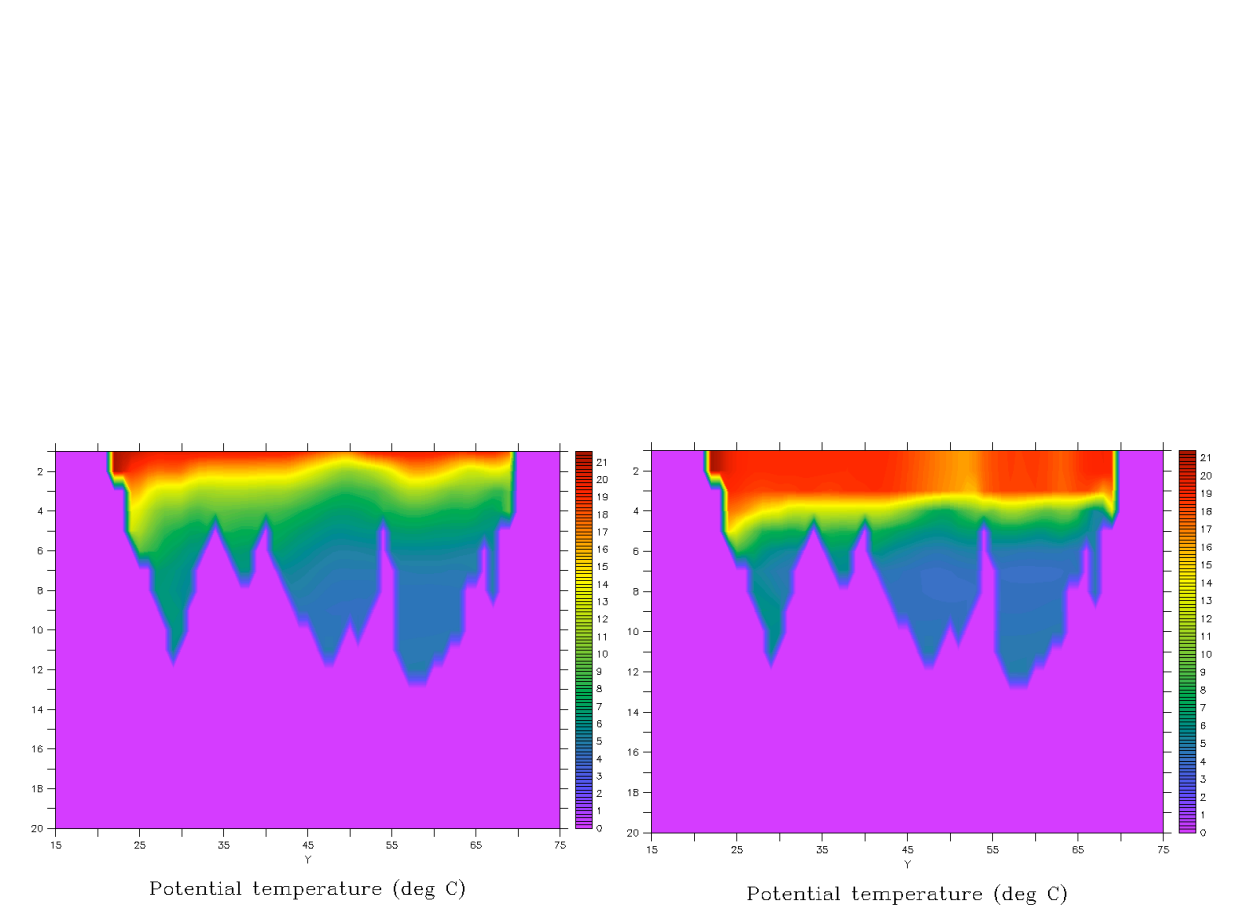

Fig. 4. The temperature profile based on Richardson vertical mixing (a) and on KPP (b).

\section{GMDD}

5, 1851-1875, 2012

Activation of 3-D CEMBS

L. Dzierzbicka-

Głowacka et al.

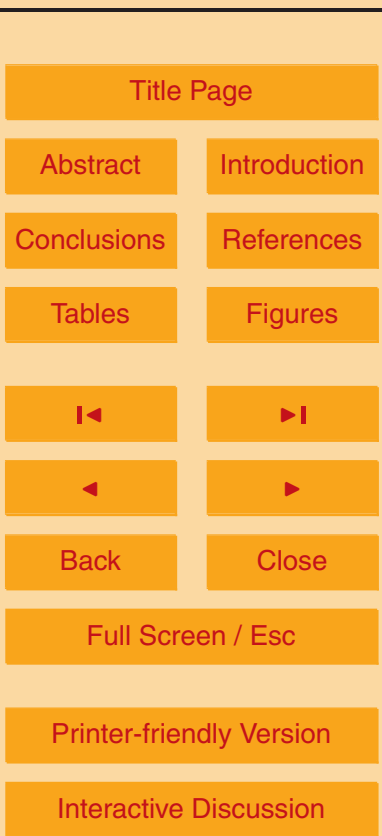




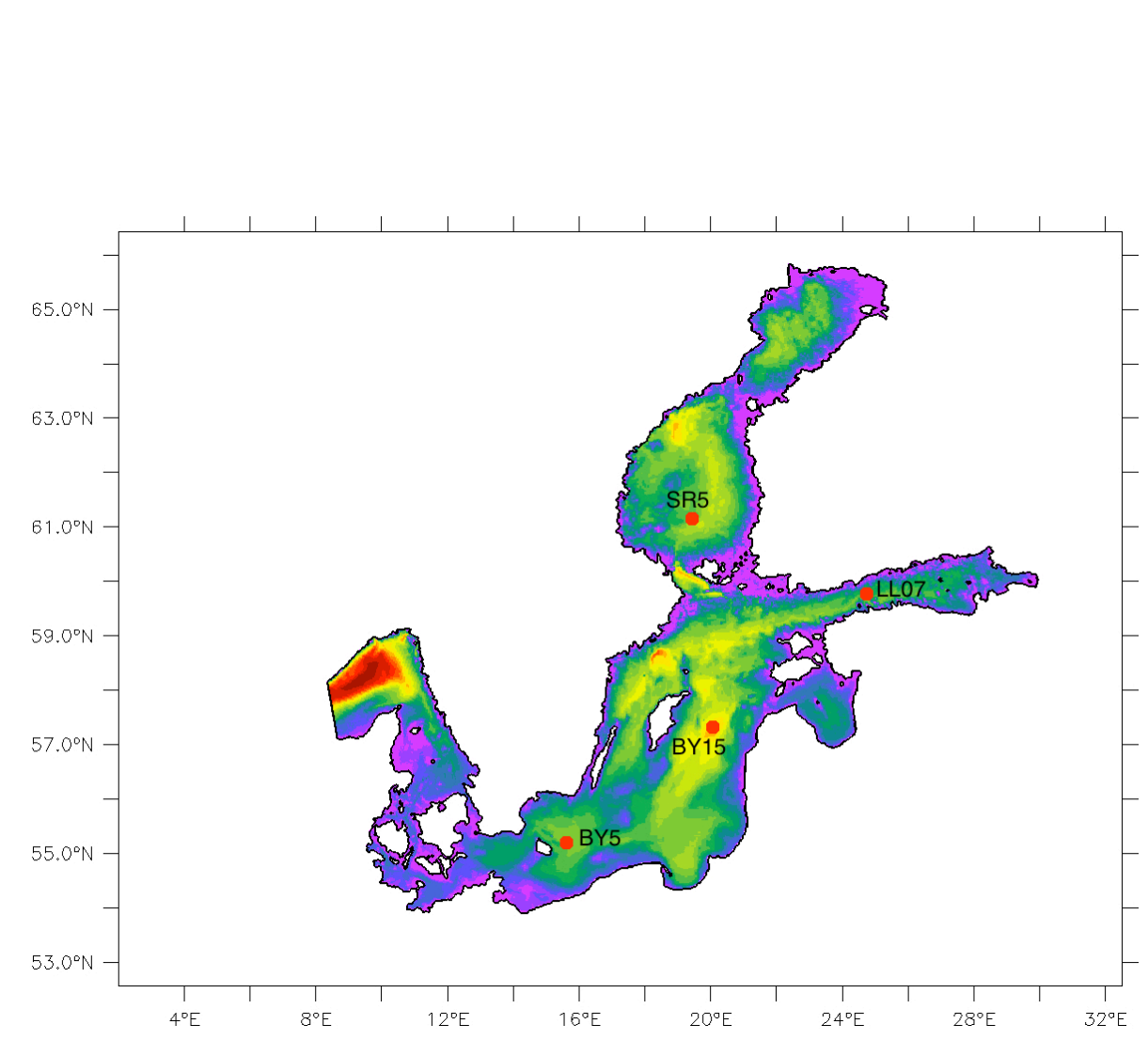

\section{GMDD}

$5,1851-1875,2012$

\section{Activation of 3-D CEMBS \\ L. Dzierzbicka- \\ Głowacka et al.}

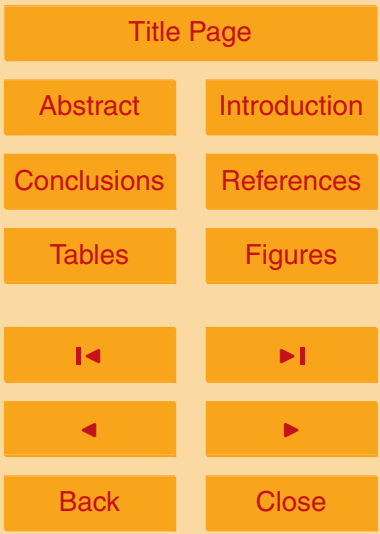

Fig. 5. Distribution of measuring buoys for which the comparison was performed (see Fig. 1 in Meier, 2002).

\section{Full Screen / Esc}

\section{Printer-friendly Version}

Interactive Discussion 

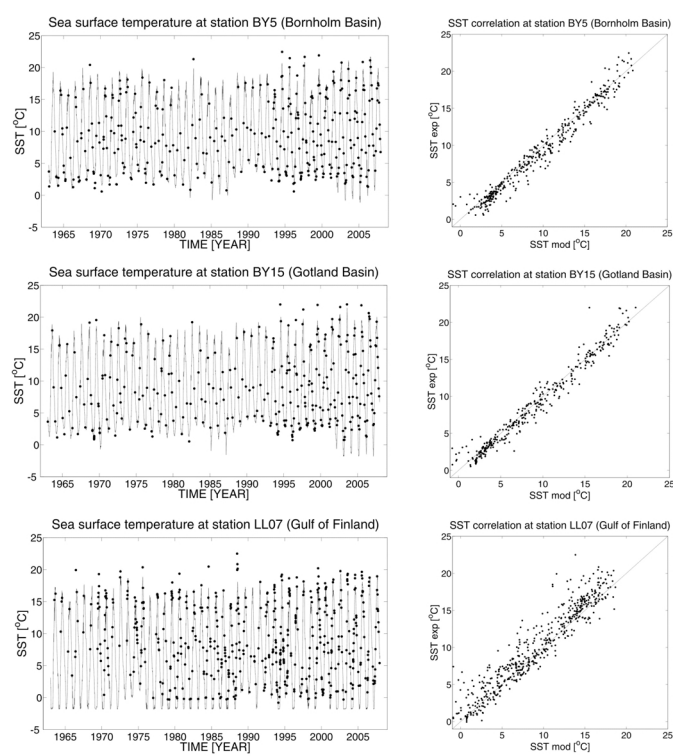

Sea surface temperature at station SR5 (Bothnian Sea)
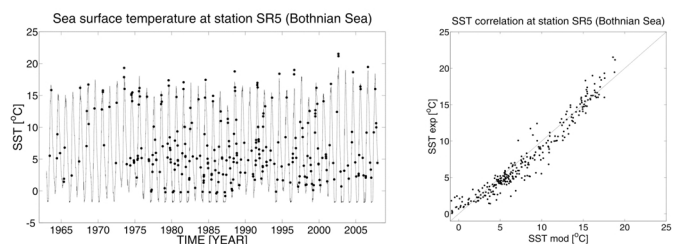

Fig. 6. Comparison of the model results of the sea surface temperature with experimental data from HELCOM http://ocean.ices.dk/helcom/Helcom.aspx?Mode=1 and SMHI http://www.smhi. se/oceanografi/oce_info_data/SODC/download_en.htm.

\section{GMDD}

$5,1851-1875,2012$

\section{Activation of 3-D} CEMBS

L. Dzierzbicka-

Głowacka et al.

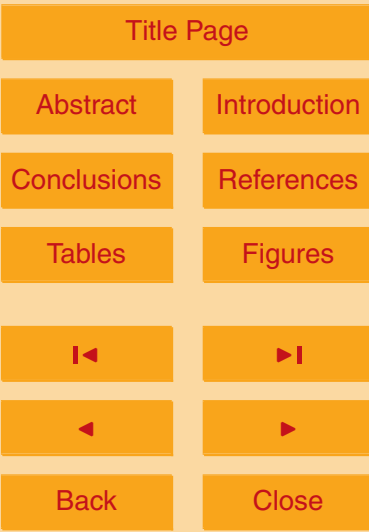

Full Screen / Esc

Printer-friendly Version

Interactive Discussion 

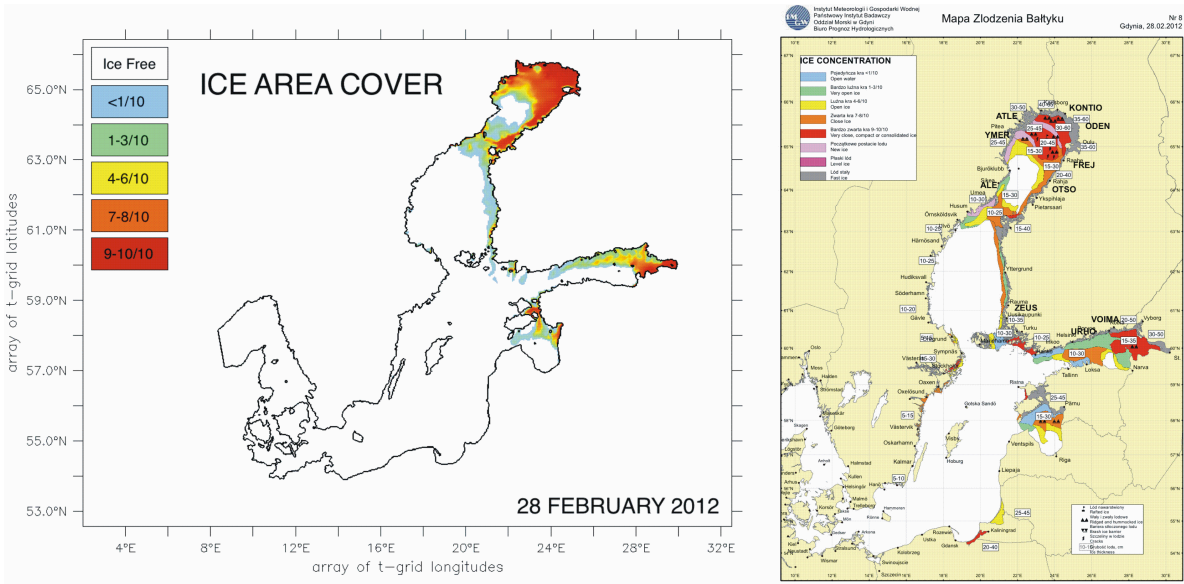

Fig. 7. Ice concentration (\%) - the results obtained from the model (a) and experimental data from meteorological service (Institute of Meteorology and Water Management) (b) for 28 February 2012.

\section{GMDD}

$5,1851-1875,2012$

\section{Activation of 3-D CEMBS}

L. Dzierzbicka-

Głowacka et al.

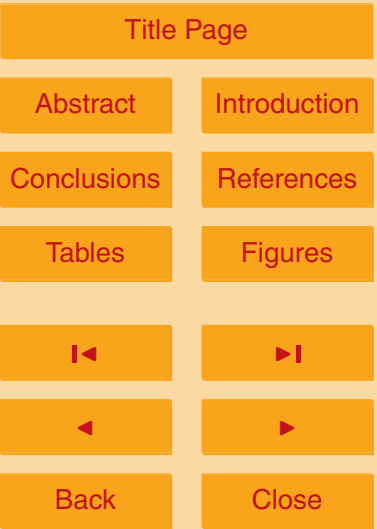

Full Screen / Esc

Printer-friendly Version

Interactive Discussion 